\title{
Investigation of Machining Parameters for Hss in Wire Electrical Discharge Grinding
}

\author{
M. Parthiban ${ }^{1 *}$, V. Krishnaraj ${ }^{1}$, S. Jothi ${ }^{2}$ \\ ${ }^{1}$ PSG College of Technology, India \\ ${ }^{2}$ Swansea University Campus, $U K$
}

*Corresponding Author: M. Parthiban, PSG College of Technology, India

\begin{abstract}
This paper presents an experimental study on the diameter accuracy and material removal rate obtained during machining of micro shafts through wire electric-discharge grinding (WEDG). Many trials were taken by machining aØ2.0mm High Speed Steel (HSS) pin to $\emptyset 0.60 \mathrm{~mm}$ under various conditions to analyze the effect of process parameters. The diameters of the shafts were measured using stereo microscope at various magnifications. The effects of various parameters were analyzed for the variation in diameter and material removal rate (MRR). The better process parameters were estimated using the signal to noise ratio and the experimental results were analyzed using analysis of variance approach.
\end{abstract}

Keywords: WEDG; micro shaft; diameter variation; MRR; optimal process parameters.

\section{INTRODUCTION}

The Electrical Discharge Machining (EDM) technology has been developed rapidly in the recent years and become important in precision manufacturing applications like die and mold making and micro machining. Wire electrical discharge machining (WEDM) is an electrical discharge machining technique used for manufacturing components with intricate shapes and profiles with the help of a numerically controlled travelling wire electrode. Material is eroded from the work piece by a number of intermittent sparks between the work piece and the wire electrode separated by a thin film of dielectric fluid. Because of its wide capabilities it has applications in various fields such as automobile, aerospace, medical and virtually all areas of conductive materials machining. Grinding with WEDM is one of the fast growing areas developed to generate cylindrical form on hard and difficult to machine materials by adding a rotary axis to WEDM. [1-5]

\section{Experimental Procedure}

The WEDG process, illustrated in Figure1, is similar to turning on a lathe. A simple RC circuit generates pulses that produce electrical discharges between the work piece (cathode) and a $250 \mu \mathrm{m}$ brass wire (anode). The discharges occur within a small gap $(\sim 2 \mu \mathrm{m})$ filled with dielectric fluid. The work piece is held horizontally in a spindle that can rotate at variable speed and its position is slowly fed in the $\mathrm{z}$ direction. The wire is supported on a wire guide, and its position is controlled in the $\mathrm{x}$ and y-directions [8]. During WEDG each electrical discharge erodes material from the work piece and the anode wire. To prevent discharges from the worn regions of the anode, the wire travels around $0.5 \mathrm{~mm} / \mathrm{s}$, through a reel and take-up system.

In order to give rotary motion to the work piece during electric discharge the spindle was fabricated and installed in the WEDM. 


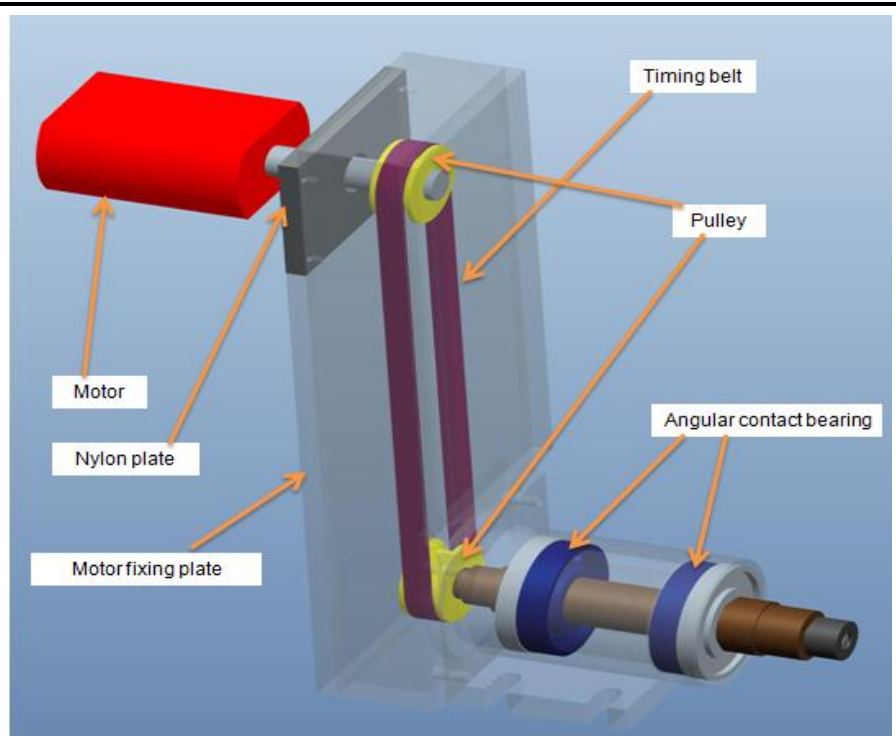

Fig1. Schematic diagram of the setup

Precision spindle is the key sub- system for wire electrical discharge grinding process [7,13]. Since this spindle is in at submerged condition the parts of this spindle have to be sealed properly. Angular contact bearing has been selected in order to avoid the run out errors. Both the spindle shaft and the motor shaft are connected using timing belt and pulley. The ER16 type Collet was assembled to the spindle in order to hold the cylindrical component of size from $\varnothing 2$ to $\varnothing 6 \mathrm{~mm}$ and it was attached to the spindle. The total spindle was covered by spindle housing and a L-bracket was used in the assembly of the rotary axis unit. In this bracket one end was attached with the spindle and the other end was attached with the motor. The speed of the motor can be controlled by VFD(Variable Frequency Drive) which ranges from 10 to 2500rpm. This bracket was fixed in the WEDM table and as the table is cathode the total unit will become as cathode, so the material can be eroded from the workpiece. It was observed that the spindle run out is the key parameter affecting consistent machining in WEDG [13$18]$.

\section{EXPERIMENTAL SET UP}

The WEDG were carried out on a MITSHUBISHI ADVANCE FA10Smachine and the photograph of the experimental setup is shown in Figure 2.The machining trials were done on HSS cylindrical rod of a $\emptyset 2 \mathrm{~mm}$ to a length of $50 \mathrm{~mm}$ by $\varnothing 0.25 \mathrm{~mm}$ brass wire.

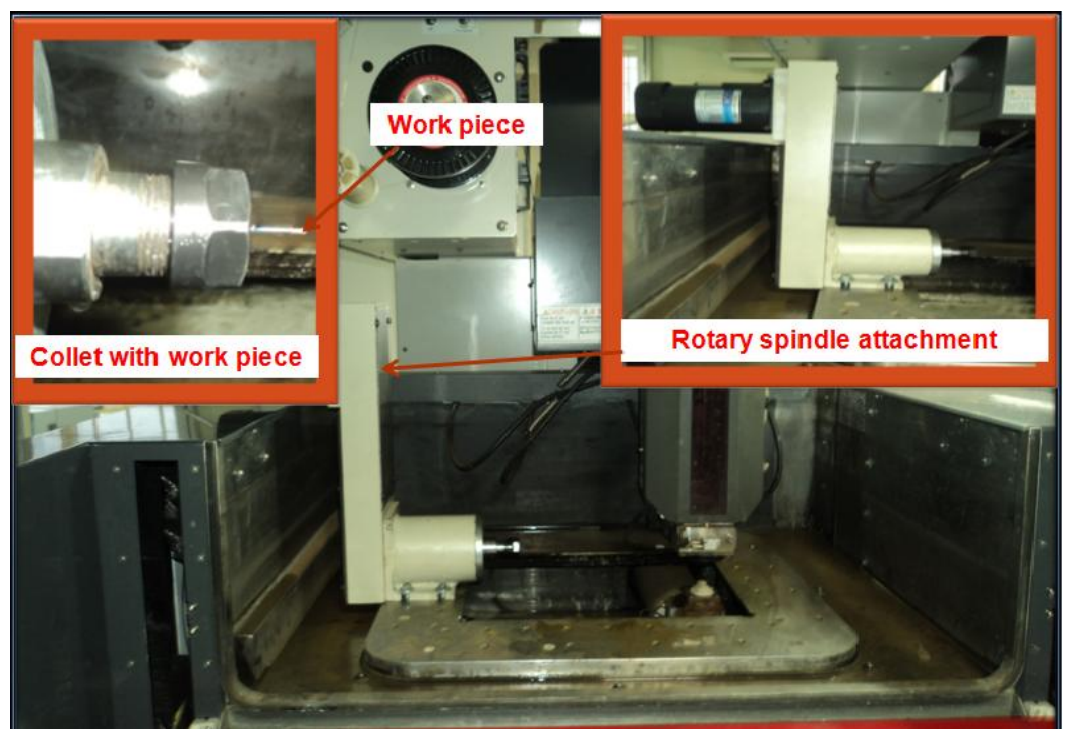

Fig2. WEDG set up on the machine

Process constants used for the WEDG machining process depends upon the material. The values will be assigned directly from the machine library once the material of the work piece was specified. The process constants for HSS material were listed in Table1. 
Table1. Process constants used for WEDG

\begin{tabular}{|c|c|}
\hline Parameter & Value \\
\hline Wire Speed (m/min) & 5 \\
\hline Current (A) & 7 \\
\hline Wire Tension (N) & 10 \\
\hline Feed Rate $(\mathrm{mm} / \mathrm{min})$ & 3 \\
\hline Number of passes & 1 \\
\hline
\end{tabular}

\section{DESIGN OF EXPERIMENTS}

Experimental design techniques are powerful approach both in product and process development area, so they have an extensive application in the engineering areas. Potential applications include product design optimization, process design development, process optimization, material selection, and many others. There are many benefits gained by many researchers and experimenters, from the application of experimental techniques.

The techniques of Taguchi [18] consist of the plan of experiments with the objectives of acquiring data in a controlled way, executing these experiments and analyze data, in order to obtain the information about the behavior of a given process. These techniques use orthogonal arrays to define the experimental plans. The treatment of the experimental results is based on the analysis of variance (ANOVA) $[18,19]$.

Table2. Plan of Experiments

\begin{tabular}{|c|c|c|c|}
\hline Parameter & Level 1 & Level 2 & Level 3 \\
\hline Spark gap (mm) & 0.18 & 0.2 & 0.22 \\
\hline Spindle Speed (rpm) & 300 & 500 & 700 \\
\hline Voltage (V) & 50 & 60 & 70 \\
\hline
\end{tabular}

Table 2shows the parameter settings for WEDG experiments. The plan of experiments is made of 9 tests in which the first column was assigned to the spark gap and the second column to the spindle speed and the third column to the voltage. In this present study interaction of factors is not considered. The outputs to be studied are diameter accuracy and the material removal rate $\left(\mathrm{mm}^{3} / \mathrm{min}\right)$. The trials are conducted for a set of cutting parameters as listed in orthogonal array. In this experimental work the three levels, three factors used to form $\mathrm{L}_{9}$ orthogonal array is shown in Table 3 .

Table3. Design of experiments

\begin{tabular}{|c|c|c|c|}
\hline S.No. & $\begin{array}{c}\text { Spark gap } \\
(\mathbf{m m})\end{array}$ & $\begin{array}{c}\text { Spindle speed } \\
(\mathbf{r p m})\end{array}$ & $\begin{array}{c}\text { Voltage } \\
(\mathbf{V})\end{array}$ \\
\hline 1 & 0.18 & 300 & 50 \\
\hline 2 & 0.18 & 500 & 60 \\
\hline 3 & 0.18 & 700 & 70 \\
\hline 4 & 0.20 & 300 & 60 \\
\hline 5 & 0.20 & 500 & 70 \\
\hline 6 & 0.20 & 700 & 50 \\
\hline 7 & 0.22 & 300 & 70 \\
\hline 8 & 0.22 & 500 & 50 \\
\hline 9 & 0.22 & 700 & 60 \\
\hline
\end{tabular}

\section{EXPERIMENTATION}

Once the identified factors are assigned to the respective columns of the orthogonal array, the physical process of performing the trial was done. Totally 9 trials with 3 replications pertrialwere conducted and compatibility values obtained in each replication and each of the trial average values were recorded. In our trials the target value for the machining is $\varnothing 0.60 \mathrm{~mm}$. The specimens were measured with stereo microscope for the actual size and recorded. The measurement and calculated records for the designed parameters were shown in Table 4. In the present work complete randomization technique was adopted for conducting the various trials.

\section{IMAGES OF MACHINED COMPONENT}

The trials were taken for different machining parameters and the image of machined component was shown in Figure3. The images of the component taken through stereo microscope and optical microscope were shown in Figures $4 \& 5$. 


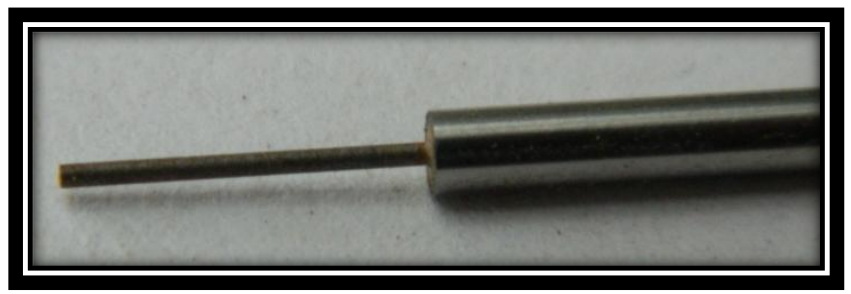

Fig3. Photograph image of machined part

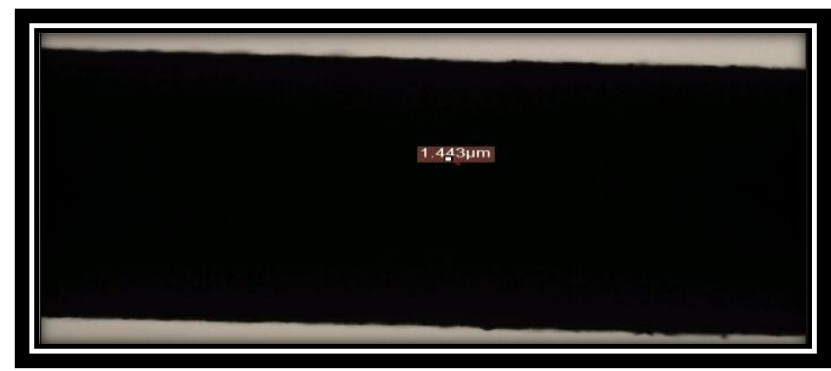

Fig4. Machined work piece (60X) (Optical microscope image)

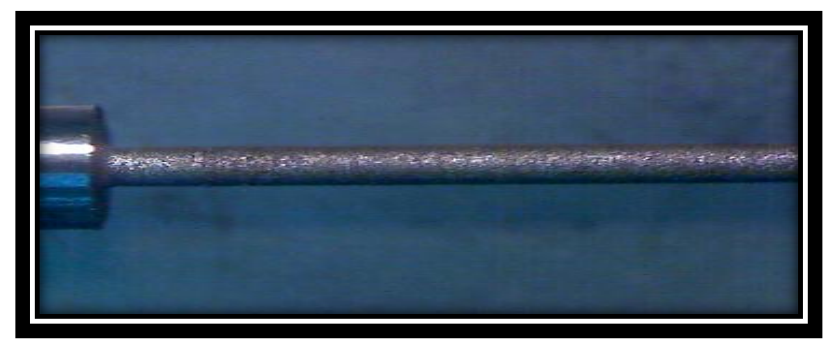

Fig5. Machined work piece (120X) (Stereo microscope image)

Table4. S/N Ratio for designed parameter

\begin{tabular}{|c|c|c|c|c|c|c|c|c|}
\hline $\begin{array}{c}\text { Trial } \\
\text { No. }\end{array}$ & $\begin{array}{c}\text { Spark } \\
\mathbf{G a p} \\
(\mathbf{m m})\end{array}$ & $\begin{array}{c}\text { Speed } \\
(\mathbf{r p m})\end{array}$ & $\begin{array}{c}\text { Voltage } \\
(\mathbf{V})\end{array}$ & $\begin{array}{c}\text { Initial Ø } \\
\mathbf{D}_{\mathbf{o}}(\mathbf{m m})\end{array}$ & $\begin{array}{c}\text { Final Ø } \\
\mathbf{D}(\mathbf{m m})\end{array}$ & $\begin{array}{c}\text { Diameter } \\
\text { Accuracy } \\
(\boldsymbol{\mu m})\end{array}$ & $\begin{array}{c}\text { Time } \\
(\boldsymbol{\mu S})\end{array}$ & $\begin{array}{c}\text { MRR } \\
(\mathbf{m m} / \mathbf{m i n})\end{array}$ \\
\hline 1 & 0.18 & 300 & 50 & 2 & 0.575 & -25 & 212 & 8.645 \\
\hline 2 & 0.18 & 500 & 60 & 2 & 0.585 & -15 & 302 & 8.618 \\
\hline 3 & 0.18 & 700 & 70 & 2 & 0.592 & -8 & 704 & 8.599 \\
\hline 4 & 0.20 & 300 & 60 & 2 & 0.609 & 9 & 340 & 8.551 \\
\hline 5 & 0.20 & 500 & 70 & 2 & 0.580 & -20 & 691 & 8.632 \\
\hline 6 & 0.20 & 700 & 50 & 2 & 0.599 & -1 & 252 & 8.579 \\
\hline 7 & 0.22 & 300 & 70 & 2 & 0.626 & 26 & 682 & 8.501 \\
\hline 8 & 0.22 & 500 & 50 & 2 & 0.620 & 20 & 261 & 8.519 \\
\hline 9 & 0.22 & 700 & 60 & 2 & 0.631 & 31 & 342 & 8.487 \\
\hline
\end{tabular}

\section{DESIGNED PARAMETERS AND ITS RESPONSE}

The $\mathrm{S} / \mathrm{N}$ ratio of diametric accuracy and material removal rate (MRR) for the designed parameter were reported in Table 5.

Table5. Designed parameters and its response

\begin{tabular}{|c|c|c|c|c|}
\hline \multicolumn{2}{|c|}{ Machining parameters } & \multicolumn{3}{|c|}{ S/N Ratio } \\
\hline $\begin{array}{c}\text { Spark gap (A) } \\
\text { mm }\end{array}$ & $\begin{array}{c}\text { Spindle speed (B) } \\
\text { rpm }\end{array}$ & $\begin{array}{c}\text { Voltage (C) } \\
\mathbf{V}\end{array}$ & MRR . $\mathbf{m m}^{\mathbf{3}} / \mathbf{m i n}$ & $\begin{array}{c}\text { Diameter accuracy } \\
\boldsymbol{\mu m}\end{array}$ \\
\hline 0.18 & 300 & 50 & 18.7353 & -27.9588 \\
\hline 0.18 & 500 & 60 & 18.7081 & -23.5218 \\
\hline 0.18 & 700 & 70 & 18.689 & -18.0618 \\
\hline 0.2 & 300 & 60 & 18.6403 & -19.0849 \\
\hline 0.2 & 500 & 70 & 18.7222 & -26.0206 \\
\hline 0.2 & 700 & 50 & 18.6687 & 0 \\
\hline 0.22 & 300 & 70 & 18.5894 & -28.2995 \\
\hline
\end{tabular}


Investigation of Machining Parameters for Hss in Wire Electrical Discharge Grinding

\begin{tabular}{|l|l|l|l|l|}
\hline \hline 0.22 & 500 & 50 & 18.6078 & -26.0206 \\
\hline 0.22 & 700 & 60 & 18.5751 & -29.8272 \\
\hline
\end{tabular}

For example, the mean $\mathrm{S} / \mathrm{N}$ ratio for the spindle speed at levels 1,2 and 3 can be calculated by averaging the $\mathrm{S} / \mathrm{N}$ ratios for the experiments 1,4 and 7.The mean $\mathrm{S} / \mathrm{N}$ ratio for each level of the other cutting parameters was computed in the similar manner. The mean $\mathrm{S} / \mathrm{N}$ for each level of the cutting parameters is summarized and called the mean $\mathrm{S} / \mathrm{N}$ response table for diametric accuracy and material removal rate.

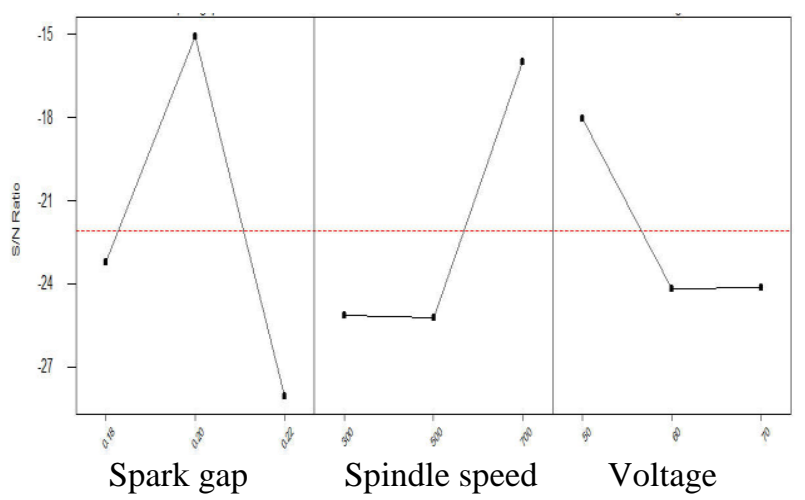

Fig6. S/N Ratio for Diametric Accuracy

The higher $\mathrm{S} / \mathrm{N}$ ratio of the process parameter gives the better diametric accuracy (Fig 6). Hence the parameters are Spark gap $=0.2 \mathrm{~mm}$, Spindle speed $=700 \mathrm{rpm}$ and Voltage $=50 \mathrm{~V}$.

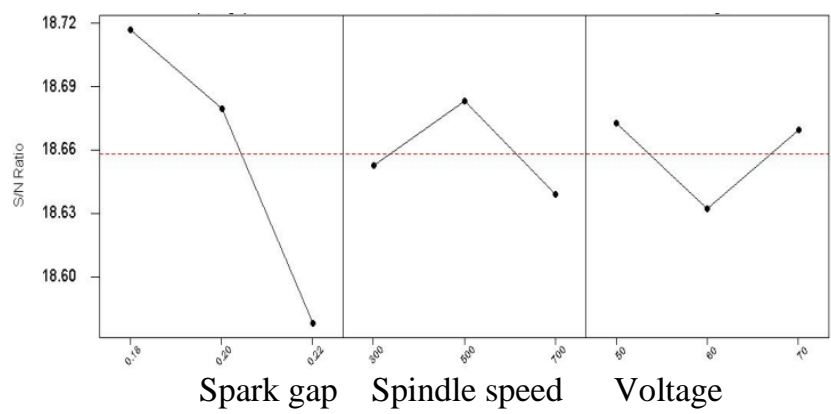

Fig7. $S / N$ Ratio for $M R R$

The higher S/N ratio in the graph (Fig.7) is the better process parameter for maximum material removal rate and the parameters are sparkgap $=0.18 \mathrm{~mm}$., spindle speed of $300 \mathrm{rpm}$, and Voltage $=50 \mathrm{~V}$.

The analysis of variance (ANOVA) establishes the relative significance of factors in terms of their percentage contribution to the response.

ANOVA is also needed for estimating the variance of error for the effects and confidence interval of the prediction error [18]. The ANOVA of diametric accuracy and MRR were shown in Tables $6 \& 7$ respectively.

Table6. ANOVA for Diametric accuracy

\begin{tabular}{|c|c|c|c|c|c|c|c|}
\hline SOURCE & DF & $\begin{array}{c}\text { SEQ } \\
\text { SS }\end{array}$ & $\begin{array}{c}\text { ADJ } \\
\text { SS }\end{array}$ & $\begin{array}{l}\text { ADJ } \\
\text { MS }\end{array}$ & $F$ & $\mathbf{P}$ & $(\% \mathrm{C})$ \\
\hline Spark gap & 2 & 374.9 & 374.9 & 187.4 & 1.25 & 0.445 & 50 \\
\hline Voltage & 2 & 128.8 & 128.8 & 64.4 & 0.05 & 0.949 & 17 \\
\hline Spindle speed & 2 & 184.8 & 184.8 & 92.4 & 0.24 & 0.806 & 24 \\
\hline Error & 2 & 75.1 & 75.1 & 37.6 & & & 9 \\
\hline Total & 8 & 763.6 & & & & & 100 \\
\hline \multicolumn{8}{|c|}{$\begin{array}{c}D F=\text { Degrees of freedom, } S E Q S S=\text { Sequential sum of squares, } A D J S S=\text { Adjacent } \\
\text { sum of squares, ADJ MS }=\text { Acjacent mean sum of squares, } \% C=\text { Percentage } \\
\text { contr bution }\end{array}$} \\
\hline
\end{tabular}


From Table 6, influence can be made such that the spark gap (50\%) and Spindle speed (24\%) have great influence of the diametric accuracy obtained, especially the Voltage (17\%) represent lower percentages of significance of contribution on the diametric accuracy.

Table7. ANOVA for MRR

\begin{tabular}{|c|c|c|c|c|c|c|c|}
\hline SOURCE & DF & $\begin{array}{c}\text { SEQ } \\
\text { SS }\end{array}$ & $\begin{array}{l}\text { ADJ } \\
\text { ss }\end{array}$ & $\begin{array}{l}\text { ADJ } \\
\text { MS }\end{array}$ & $\mathbf{F}$ & P & $(\% \mathrm{C})$ \\
\hline Spark gap & 2 & 0.03002 & 0.03002 & 0.01501 & 31.42 & 0.031 & 81 \\
\hline Voltage & 2 & 0.00296 & 0.00296 & 0.00148 & 3.09 & 0.244 & 8 \\
\hline $\begin{array}{l}\text { Spindle } \\
\text { speed }\end{array}$ & 2 & 0.00296 & 0.00296 & 0.00148 & 3.09 & 0.244 & 8 \\
\hline Error & 2 & 0.00096 & 0.00096 & 0.00048 & & & 3 \\
\hline Total & 8 & 0.03689 & & & & & 100 \\
\hline
\end{tabular}

From Table 7, influence can be made such that the Spark gap (81\%) have great influence of the material removal rate obtained.

The error associated to the ANOVA table for the diametric accuracy is approximately $9 \%$, and for the MRR is approximately $3 \%$.

By analyzing the results it is understood that the spark gap (50\%) and spindle speed (24\%) have great influence of the diametric accuracy obtained. The Voltage value (17\%) represents lower percentages of significance on the diametric accuracy. The spark gap $(81 \%)$ have great influence of the material removal rate obtained. It is understood that lower spark gap can lead to higher MRR.

\section{Optimal Machining Parameters}

The optimum machining parameters for diameter accuracy and material removal rate (MRR) are shown in Table 8.

Table8. Optimum machining parameters

\begin{tabular}{|c|c|c|c|}
\hline Parameter & Spark Gap & Spindle Speed & Voltage \\
\hline Diameter Accuracy & 0.20 & 700 & 50 \\
\hline MRR & 0.18 & 300 & 50 \\
\hline
\end{tabular}

\section{Machining Trials For ASPECt RATio}

Based on the diametric accuracy parameters given in Table 8 trials were taken in order to achieve the better aspect ratio i.e. L/D ratio and the images of those are shown below. With the current set up the aspect ratio of 25 [Fig 8] and 16[Fig 9] were achieved.

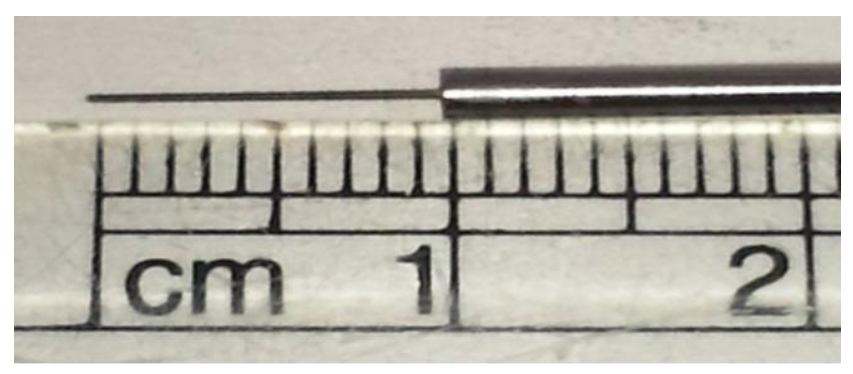

Fig8.Ø0.40 machined for length $10 \mathrm{~mm}$

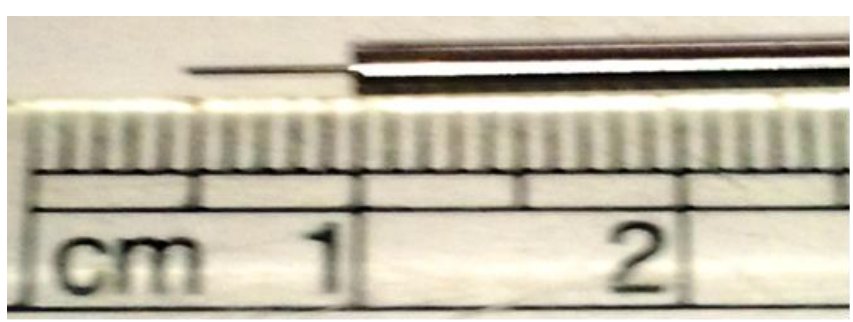

Fig9. Ø0.30 machined for length $6 \mathrm{~mm}$ 


\section{CONCLUSiOnS}

In the present work an experimental set up has been fabricated and WEDG was carried out.

Micro rods of $\varnothing 0.3 \mathrm{~mm}$ to a length of $6 \mathrm{~mm}$ and $\varnothing 0.4 \mathrm{~mm}$ to a length of $10 \mathrm{~mm}$ were produced. [Aspect ratios of $16 \& 25$ were achieved].

From the experimental results it is understood that the spark gap has $50 \%$ influence on the diametric accuracy and $81 \%$ for the material removal rate.

In the present set up the spindle run out is $32 \mu \mathrm{m}$ which may be instrumental factor with other process parameters for not able to achieve more aspect ratios in machining as the work piece breaks while machining for high aspect ratio.

By controlling the spindle run out more trials can be conducted to find the optimal process parameter to machine higher aspect ratio.

\section{REFERENCES}

[1] Spedding.T.A, Wang.Z.Q(1997) Study on modeling of wire EDM process, Journal of Materials Processing Technology $69: 18-28$.

[2] Masuzawa.T, Tonshoff H.K(1997) Three-dimensional micromachining by machine tools, Annals of the CIRP46 : 621-628.

[3] Liao Y.S., Chien S.T, Lin C.S (2005), Development of a high precision tabletop versatile CNC wire EDM for making intricate micro parts, J. Micromechanics Microengineering, 15: 245-253

[4] Schoch.A, Foster.A, Menz.W (2005) Micro wire EDM for high aspect ratio 3D micro structuring of ceramics and metals, Microsyst Technol 11:250-253

[5] Yan M.T, Huang C.W, Fang C.C, Chang C.X (2003) Development of a prototype micro-wire EDM machine, J.Mater. Process Technol 149:99-105

[6] Yan M., Chien H. (2007), Monitoring and control of the micro wire-EDM process, Int. J Mach Tools Manuf 47:148-157

[7] Rees.A, Brousseaua. E, Dimova.S.S, Gruberb.H, Paganettib,I, (2008) Wire electro discharge grinding: surface finish optimization, J Multi-Material Micro Manufacture

[8] Chris Morgan, Shelby Shreve,Ryan Vallance..R, (2003), Precision Of Micro Shafts Machined With Wire Electro-Discharge Grinding, Proceedings of the ASPE Winter Topical Mtg on Machines and Processes for Micro-Scale, Meso-Scale Fabrication, Metrology and Assembly

[9] Uhlmann.E, Piltz.S, Oberschmidt.D,(2008) Machining of micro rotational parts by wire electrical discharge grinding, Prod. Eng. Res. Devel. 2:227-233

[10] Masuzawa.T,Fujino.M,Kobayashi.K(1985) Wire electro-discharge grinding for micro-machining, CIRP Annals, 34:1: 431-434.

[11] Pradhan.B.B B. B, Masanta.M, Sarkar.B.R, Bhattacharyya.B(2008) Investigation of electro-discharge micro-machining of titanium super alloy, Int J Adv ManufTechnol41:1094-1106

[12] Janardhan.V, Samuel.G.L, (2010) Pulse train data analysis to investigate the effect of machining parameters on the performance of wire electro discharge turning (WEDT) process, International Journal of Machine Tools \& Manufacture, 50: 775-788

[13] Somasekhar.K.P (2010) Ph D Thesis on Theoretical and experimental investigations on micro Electric Discharge Machining ( $\mu$-EDM) processes, National Institute of Technology, Calicut.

[14] Pham DT, Dimov SS, Bigot S, Ivanov A, Popov K (2004) Micro-EDM: recent developments and research issues. J Mater Process Technol 149(1-3):50-57

[15] Jun Qu, Albert J.Shih, Ronald O.Scattergood, (2002),"Development of the Cylindrical Wire Electrical Discharge Machining Process", Part1: Concept, Design and Material Removal Rate, Transactions of the ASME 702 / Vol.124

[16] Jun Qu, Albert J.Shih, Ronald O.Scattergood, (2002),"Development of the Cylindrical Wire Electrical Discharge Machining Process", Part2: Surface Integrity and Roundness, Transactions of the ASME 708 / Vol.124

[17] Nihat Tosun, (2003), "The Effect Of Cutting Parameters On Performance Of WEDM", KSME International journal, Vol.17: 816-824

[18] Mahapatra S S, Amar Patnaik (2006), "Parametric Optimization Of WEDM Process Using Taguchi Method", J. Braz. Soc. Mech. Sci. \& Eng.Rio de Janeiro, Vol.28 No.4

[19] Hadad M J, Tajik M, Mohammadi A, (2009), "An Experimental Investigation Of Cylindrical Wire Electrical Discharge Turning Process Using Taguchi Approach", International Journal Of Material Forming, Vol. 2: 167-179. 


\section{AUTHOR's BIOGRAPHY}

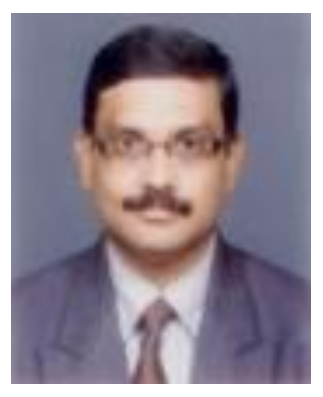

Parthiban, is an Engineering \& IT professional with a Masters Degree in Engineering and having 7 Years of cross-functional experience in SAP/ Manufacturing/Automobile industries. He has got nearly 7 years of experience with Machine Tool and Automobile engineering industries in Design, Quality Control and performed as a Lead Assessor for ISO 9000 and in preparation of Quality System Procedures and other relative documents and also having a very good knowledge in Inspection and Metrology Lab activities. Presently working in PSGCT in Mechanical Engineering department and doing the research in micro machining.

Citation: M. Parthiban et al. (2017). Investigation of Machining Parameters for Hss in Wire Electrical Discharge Grinding, International Journal of Modern Studies in Mechanical Engineering (IJMSME), 3(3), pp.18-25, DOI: http://dx.doi.org/10.20431/2454-9711.0303003.

Copyright: () 2017 M. Parthiban This is an open-access article distributed under the terms of the Creative Commons Attribution License, which permits unrestricted use, distribution, and reproduction in any medium, provided the original author and source are credited 